\title{
Invasive populations of Brassica nigra express fewer glucosinolate compounds and are more deterrent to generalist herbivores than native populations
}

\author{
Ayub Oduor ${ }^{1}$ \\ ${ }^{1}$ Technical University of Kenya School of Pure and Applied Sciences
}

May 5, 2020

\begin{abstract}
The shifting defence hypothesis attributes the invasion success of many plant species to the species' post- introduction evolution of traits that confer high fitness including reduced allocation to physiologically and ecologically costly chemical defence compounds against herbivores. However, to date, most of the studies that compared invasive and conspecific native plants for differences in defence compounds focused only on one or a few compounds. Thus, it remains unclear whether invasive plants may evolve a lower diversity of defence compounds in response to a simplified herbivore community assemblages in the introduced range. Therefore, the present study used B. nigra plants from 11 invasive- and 14 native range populations to test whether invasive B. nigra plants: i) express a lower diversity of glucosinolate compounds and higher concentration of a single dominant glucosinolate compound owing to a reduced diversity of herbivores in the introduced range; ii) are less preferred by generalist herbivores and attract more specialist herbivore species than B. nigra from the native range when grown in a common garden in the native range; iii) are less preferred by generalist herbivores than native-range B. nigra in no- choice feeding bioassays. In support of the shifting defence hypothesis, invasive B. nigra plants expressed a lower diversity of glucosinolates and a higher concentration of sinigrin (a major glucosinolate compound in B. nigra) than native-range B. nigra plants. Moreover, the invasive B. nigra plants were more deterrent to two generalist herbivore species in no-choice feeding bioassays than native B. nigra plants. Brassica nigra plants that expressed higher concentrations and diversities of glucosinolate compounds were visited by a more diverse specialist herbivore community than B. nigra plants with low concentrations and diversities of glucosinolates. The biogeographical differences in glucosinolate profiles observed here may be the result of differential herbivore selection pressures in the respective invaded and native ranges.
\end{abstract}

\section{Hosted file}

Manuscript.doc available at https://authorea.com/users/301919/articles/431848-invasivepopulations-of-brassica-nigra-express-fewer-glucosinolate-compounds-and-are-moredeterrent-to-generalist-herbivores-than-native-populations 